\title{
ESTRATÉGIAS DE EMPODERAMENTO DOS AUXILIARES E TÉCNICOS DE ENFERMAGEM NA EQUIPE MULTIPROFISSIONAL DE SAÚDE MENTAL
}

Eixo temático: Avaliação e Qualidade do Cuidado

\section{Introdução}

As mudanças nas políticas de assistência em Saúde Mental vêm requerendo profissionais comprometidos com atendimento com equidade e humanização, buscando qualidade e eficácia. Os técnicos e auxiliares de enfermagem são os profissionais que mantêm contato mais próximo e constante com os pacientes em um serviço de saúde, mas costumam ter pouca participação nos espaços decisórios da equipe multiprofissional.

\section{Objetivo}

Relatar a experiência de estratégias de empoderamento dos auxiliares e técnicos de enfermagem na equipe multiprofissional de um Centro de Atenção Psicossocial - CAPS.

\section{Metodologia}

Pesquisa de campo, descritiva, contemplando o relato de experiência de 12 anos de trabalho da equipe de enfermagem em um CAPS administrado por organização social.

\section{Desenvolvimento}

Ao iniciar a gestão do CAPS, em 2007, a equipe de nível médio era identificada como equipe de apoio, pois atuava prioritariamente no posto de enfermagem, ambiência e refeitório auxiliando em atividades como medicação e cuidados de higiene, sem compartilhar esse trabalho com os demais profissionais. A gestão de enfermagem e a equipe multidisciplinar implantaram estratégias ao longo desses doze anos visando o empoderamento desses profissionais para atuação em espaços valiosos do serviço, como discussão de casos e projetos terapêuticos singulares em reunião de equipe.
Estratégias implantadas para o Empoderamento dos Auxiliares e Técnicos de Enfermagem

- Distribuição das tarefas previamente exclusivas da enfermagem entre demais membros da equipe (ex: lavanderia, refeitório e elaboração de manual multiprofissional referente às atividades);

- Participação, criação e/ou coordenação de atividades assistenciais anteriormente exclusivas de profissionais de nível Superior: acolhimento, oficinas, atendimento em grupo, individual e familiar, visitas domiciliares de cunho terapêutico e não exclusivamente medicamentoso;

- Campo de estágio para cursos técnicos de enfermagem;

- Abertura de 80 vagas anuais para realização de um curso gratuito de Capacitação em Saúde Mental e Psiquiatria em sua nona edição.

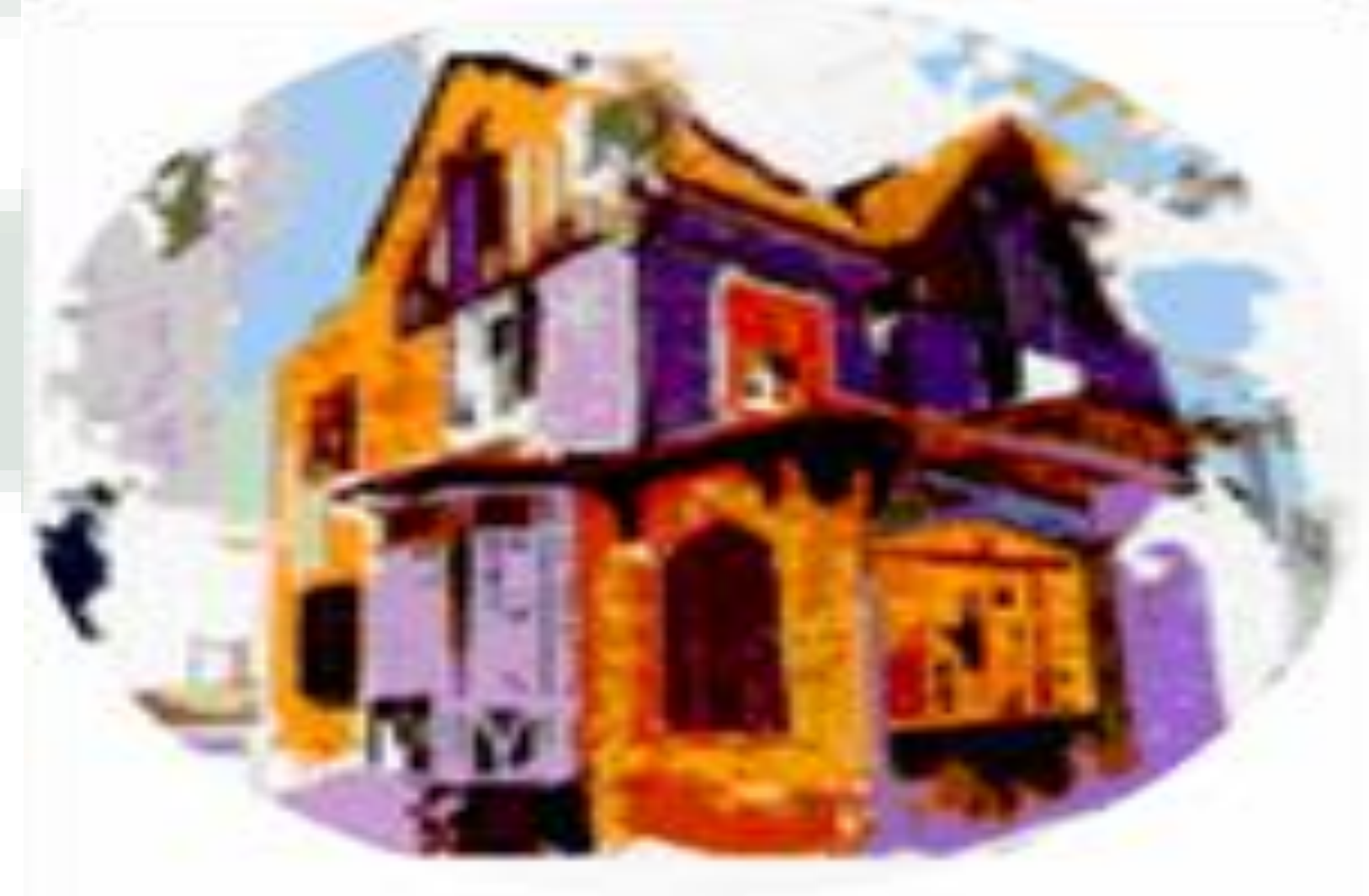

\section{Conclusão}

As mudanças implantadas permitiram evolução da atuação da Equipe de Saúde Mental, incorporando o olhar e o saber do profissional de Nível Médio para o cotidiano da instituição, trazendo não apenas 0 empoderamento dos auxiliares e técnicos de enfermagem, mas também ganhos para a equipe e para o tratamento para o usuário. 